\title{
The Leveraged ETF Inefficiency in Trending \& Range-Bound Markets: An Application Case Study for a 3x Leveraged Gold Miners ETF
}

\author{
Vasiliki A. Basdekidou ${ }^{1}$ \\ ${ }^{1}$ SRFA Aristotle University of Thessaloniki, Greece \\ Correspondence: Vasiliki A. Basdekidou, Special Research Fund Account (E $\Lambda$ KE), Aristotle University of \\ Thessaloniki, Greece. Tel: 30-697-277-5475. E-mail: Vasiliki.Basdekidou@gmail.com
}

Received: January 29, 2017

Accepted: February 25, 2017

Online Published: May 30, 2017

doi:10.5539/ijef.v9n7p1

URL: https://doi.org/10.5539/ijef.v9n7p1

\begin{abstract}
The main goal of this paper is to introduce the leveraged ETF die-down price action technical market anomaly (leveraged ETF anomaly), and then to discuss the temporal dimension and the subsequent (time-series) functionalities of this anomaly (temporal leveraged ETF anomaly). Our approach not only challenging the efficient-market hypothesis with regards to constantly declining leveraged ETF price action course, but also has a temporal dimension because it uses the Jesse Livermore's "psychological time" as parameter in both functions: (i) "emotional control" for opening position at the beginning of an intraday or short-term move and thereafter for holding this position; and (ii) in "money risk management - exit policy" for closing position. Traditional fundamental analysis theories and technical analysis rules and approaches are not able to interpret the die-down (i.e. a constantly declining in a mid- and long-term basis) leveraged ETF price action course. Instead, a rational dynamic and temporal representative agent could explain and document better this anomaly and this is the case of this article (i.e. trading exploitation functionality). The presented research shows that the proposed temporal leveraged ETF anomaly accumulates profit entirely overnight in sideways and in choppy markets, while in a trending market the profit occurs intraday. These findings for the leveraged ETF instruments reject classical theories of trending and sideways markets returns. Hence, (i) in a sideways or in a choppy market, a well designed overnight-position return strategy based on temporal leveraged ETF anomaly; and (ii) in a trending market, a well designed daytime-position return strategy based on temporal leveraged ETF anomaly as well, could gain benefit at the expense of hedgers and long-term investors respectively. After back-testing our research in available 5-year data for the JNUG 3x leveraged ETF (gold miners juniors), we found that overnight-position speculators, in sideways or choppy markets, profit from the proposed temporal leveraged ETF trading strategy approach at the expense of hedgers; and daytime swing traders, in trending markets, profit from the proposed temporal leveraged ETF trading strategy approach at the expense of long-term investors.
\end{abstract}

Keywords: market inefficiency, leveraged ETF, trading, implied volatility, temporal trading functionalities

\section{Introduction}

The main goal of this paper is to introduce the leveraged ETF (LETF; exchange-traded fund) die-down price action technical market anomaly (leveraged ETF anomaly), and then to discuss the temporal dimension and the subsequent (time-series) functionalities of this anomaly (temporal leveraged ETF anomaly) (Leung, Lorig, \& Pascucci, 2015). As an application domain we choose the SEC-approved (U.S. Securities and Exchange Commission; SEC.gov) category of leveraged "instruments"; a risky trading tool for mom-and-pop inexperienced investors who play the market casually and rely on brokers to manage their portfolios. Actually, these "instruments" are neither stocks (securities) nor mutual funds; they're just packaged products - of an underlined asset (e.g. WTI ETN, Gold miners ETF) - using derivatives to create daily leverage. Our approach not only challenging the efficient-market hypothesis with regards to constantly declining leveraged ETF price action course, but also has a temporal dimension because it uses the Jesse Livermore's "psychological time" as parameter in both functions: (i) "emotional control" for opening position at the beginning of an intraday or short-term move and thereafter for holding this position; and (ii) in "money risk management - exit policy" for closing position. Traditional fundamental analysis theories and technical analysis rules and approaches could not interpret and "trade" the die-down (constantly declining in a mid- and long-term basis) leveraged ETF price 
action course. Instead, a rational dynamic and temporal representative agent could explain and document better this anomaly and this is the case of this article (i.e. trading exploitation functionality). The presented research shows that the proposed temporal leveraged ETF anomaly accumulates profit entirely overnight in a range-bound market, while in a trending market the profit occurs intraday. These findings for the leveraged ETF instruments reject classical theories of trending and sideways markets returns. Hence, (i) in sideways range-bound and in choppy markets, a well designed overnight-position return strategy based on temporal leveraged ETF anomaly; and (ii) in a trending market, a well designed daytime-position return strategy based on temporal leveraged ETF anomaly as well, could gain benefit at the expense of hedgers and long-term investors respectively. After back-testing our research in available 5-year data for the JNUG 3x leveraged ETF (gold miners juniors), we found that overnight-position speculators, in sideways or choppy markets, profit from the proposed temporal leveraged ETF trading strategy approach at the expense of hedgers, and daytime swing traders, in trending markets, profit from the proposed temporal leveraged ETF trading strategy approach at the expense of long-term investors (Leung, Lorig, \& Pascucci, 2015; Little, 2010).

\subsection{Problem Introduction}

Trading is regarded as a temporal historical living system (Styliadis, 2007; Styliadis \& Vassilakopoulos, 2005) with a number of time-based anomalies challenging and contradicting the efficient-market hypothesis (EMH) and initiating relative trading functions. Anomalies in the markets appear on occasion and challenge the EMH. The EMH theory asserts that the current price of a security reflects all public and private information about that security. Thus, a "market" (e.g. a stock or 3x instrument) follows the path of a random walk hypothesis (RWH) (derived from a weak-form EMH), the premise of which states that current prices are not dependent on past prices and are normally distributed over time (Malkiel, 2003; Moskowitz, Ooi, \& Pedersen, 2012). According to EMH and RWH, changes in price are due to current news or events, which are impossible to predict in advance. The current article says that the EMH and RWH both ignore the realities of the markets (emotional factors), in that participants are not completely rational and that current price moves are not independent of previous moves.

Over the years, many studies have presented data about what academics call "market anomalies". Typically, for these anomalies, there are three common classifications: Fundamental, Technical, and Calendar-based anomalies. Also, there is another class of anomalies that simply could be referred to as "temporal" because of the time-series (timing) functionality involved. In this article we will discuss two of these "temporal" anomalies, called the temporal Momentum market anomaly and the temporal Trend-reversal market anomaly. These anomalies could be characterized as trading strategy approaches rather than as documented trading strategies; but if they parameterized by the time and particular by the Livermore's psychological time, then they would respected as time-series temporal trading strategies. Historically, market anomalies display great timing-based trading functionalities, resulting in excellent return, profit, and wealth growth opportunities (Ogden \& Wu, 2013; Basdekidou, 2015). These temporal trading functionalities (e.g. the psychological time at the beginning of a move in trading according to Livermore (1940/2001) have not been fully documented yet. For instance, the observed mispricing in daytime and overnight trading sessions could be regarded as a temporal market anomaly offering a number of Temporal Trading Functionalities (TTF). The TTF trading functionalities are function elements of an $\mathrm{nD}$ array (with the $1^{\text {st }}$ dimension the Livermore's "psychological time"; the $2^{\text {nd }}$ dimension the Livermore's "emotional control", the $3^{\text {rd }}$ dimension classical Price Action Patterns, the $4^{\text {th }}$ dimension classical Candlestic Patterns, etc.) and characterized by embedded time-based behavioral biases rich in psychological time, emotional control, and risk management functions. The TTFs have had a dominant position in securities, futures, Forex, and option markets (Leung et al., 2015; Blackrock, 2010; Basdekidou, 2016a; Basdekidou, 2016b; Basdekidou \& Styliadou, 2017; Basdekidou, 2017a; Basdekidou, 2017b; Basdekidou, 2017c).

A typical TTF trading functionality example: As a typical TTF example, in a choppy market and for a LETF pair, consider the following trading plan: In case of an opening gap-down (e.g. opening bearish traps fuelling by institutions, pre-market announcements, reports, etc.) for the last-week more bullish $3 x$ counterpart instrument, buy it at its first price action reaction (i.e. after a failed double bottom) and during the "psychological time" period of the first $30 \mathrm{~min}$ (09:30 - 10:00 am) of the trading session $\rightarrow$ hold position overnight ("emotional control") $\rightarrow$ sell this position next day during the morning session ("psychological time").

Behavioral models of leveraged and inverse ETFs were examined in detail by Blackrock analysts Cheng and Madhavan (2009); Guedj, Guohua, and Craig (2010); and Guedj and Huang (2010). On the other hand, no behavioral models related to temporal leveraged ETF trading strategy approach are presented in corporate finance literature. In this domain, understanding Livermore's "psychological time", "emotional control", and "money risk money - exit policy" is critical for market and securities evaluation and trading purposes (Livermore, 1940/2001; Lefèvre, 1923/2010). Lou et al. (2016) deliver remarkable new evidences about daytime and 
overnight returns, operated as time-series parameters to the proposed in our article temporal market anomalies. According to Lou et al. research, nearly $100 \%$ of the abnormal (i.e. market anomalies) returns on momentum strategies occur overnight. On the other hand, according to Asness, Moskowitz, and Pedersen (2013) the average intraday component of momentum profit is statistically insignificant. Their findings are subject to a number of controls and risk-adjustments (Ahn, Conrad, \& Dittmar, 2003). According to these papers, as well as to the findings of the current paper presented in Tables 1-2 (Section 4), the overnight return time-series parameter is bigger among large-cap stocks, 3x ETF/ETN instruments, and stocks with relatively large prices (Vayanos \& Woolley, 2013). The presented results in Tables 1-2 are inconsistent with the simple classical theories and explanations about intraday and overnight trading return. Hence, this inconsistency could be characterized as a new (temporal) market anomaly not belonging to well-known fundamental, technical or calendar-based anomalies (Little, 2010; Blackrock, 2010; Edelen, Ince, \& Kadlec, 2015).

\subsection{The Daytime \& Overnight Returns as Time-Series Parameters}

The two trading rules, for the introduced temporal momentum return anomaly, are characterized as time-series related to position timing (overnight or intraday) and they are defined as follows:

The Overnight-position return rule (strategy):

Buy at the "Close" (i.e. during the last 5 min: 3:55 - 4:00 pm EST) of the current daily session

Hold position during the overnight period

Sell at the "Open" (i.e. during the first 30 min: 9:30 - 10:00 am EST) of next day's session

The Intraday-position rule (strategy):

Buy at the "Open" (i.e. during the first 30 min: 9:30 - 10:00 am EST) of the current daily session Hold position during the daily session

Sell at the "Close" (i.e. during the last 5 min: 3:55 - 4:00 pm EST) of the current daily session

The above two (2) trading rules were following strictly in the back-testing procedure (1.1.2012 - 31.12.2016 data) for producing the statistical information presented in Tables 1-2 (Section 4).

In our proposed trading strategy, both, the daytime and the overnight returns are regarded as time-series parameters. Then, the daytime versus overnight returns could be characterized as a comparative TTF and can be studied by analyzing the differences in returns between strategies based on trading positions holding: (i) during the day's session (defined herein as regular NYSE trading hours: 9:30 am - 4:00 pm EST); and (ii) the overnight period. In the current article, for back-testing purposes of both returns, we use the trade data of the SPDR S\&P 500 ETF (SPY), from January 1, 2000 to June 30, 2016. For this comparative TTF we define the daytime return as the difference in pricing between the day's open and the day's close; and the overnight return as the difference between the day's close and the following morning's open (Nguyen \& Tran, 2016).

\subsection{Paper's Motivation}

The link between temporal (time-series) momentum returns and the positions of speculators, swing traders, hedgers, and long-term investors, indicates that speculators, in sideways range-bound or choppy markets, profit from time-series momentum trading strategies at the expense of hedgers; and daytime swing traders, in trending markets, profit from time-series momentum trading strategies at the expense of long-term investors.

In this domain, the main target of the current article is disparate. Actually, we investigate both: (a) whether the overnight shareowners (as momentary speculators), in a range-bound market, profit from the application of the overnight holding TTF as a time-series parameter, to the trading approach introduced in this paper as temporal leveraged ETF anomaly; and (b) whether the daytime shareowners (as swing traders), in a trending market, profit from the application of the intraday holding TTF as a time-series parameter, to the trading approach introduced in this paper as temporal leveraged ETF anomaly. It is notable that, the results obtained does depend on the trading instrument (3x leveraged ETF/ETN; index-based ETF; etc.) and therefore always an adaptive personalized functionality is involved ("volatility" in case of the trading instrument and "user profile" for the case of the investors, traders, and momentary speculators).

\subsection{Paper's Structure}

The rest of the article is organized as follows: In Section 2 ("The leveraged ETF technical market anomaly") the die-down price action technical market anomaly is discussed and demonstrated through the paradigm of the JNUG/JDST 3x ETF pair. In Section 3 ("The temporal leveraged ETF anomaly") the innovative term temporal leveraged ETF market anomaly is defined, analyzed by using the Livermore's "psychological time" as 
parameter, and its functionality is documented in "Emotional Control" and "Money Risk Management - Exit Policy" trading tactic's functions. In Section 4 ("Performance Evaluation - Results") by back-testing 5-year data for the JNUG/JDST 3x pair, the performance of a proposed trading strategy approach based on the introduced temporal leveraged ETF, in daytime-position and overnight-position return trading strategies for both market conditions (range-bound and trending) is demonstrated. Finally, Section 5 ("Conclusions \& Discussion") summarizes the conclusions and discusses paper's innovations and contributions.

\section{The Leveraged ETF Technical Market Anomaly}

In this Section the die-down price action technical market anomaly for the leveraged ETF is discussed and demonstrated through the paradigm of the JNUG/JDST 3x ETF instrument pair (Direxion, 2017). The JNUG instrument is the $3 \mathrm{x}$ leveraged counterpart, while the JDST instrument is the $3 \mathrm{x}$ inverse-leveraged counterpart of the pair. These counterparts, despite the fact that both have the same reference the junior gold miners ETF (GDXJ; Van Eck, 2017) in exactly the same percentage ratio but in an opposite manner (i.e. $+3 \mathrm{x}-3 \mathrm{x}$ ), actually both follow a constantly declining price action procedure and this strange behave, explained statistically by local-stochastic volatility models (see Cheng \& Madhavan, 2009; Avellaneda \& Zhang, 2010), is a typical technical market anomaly. In fact, in computational finance theory, leveraged (ETF) implied volatility from (ETF) dynamics (Leung et al., 2015).

In following Figures 1, and 2, this die-down price action course for both counterparts of the JNUG/JDST pair is obvious. These figures were created in TC2000 trading software platform (Worden, 2017).

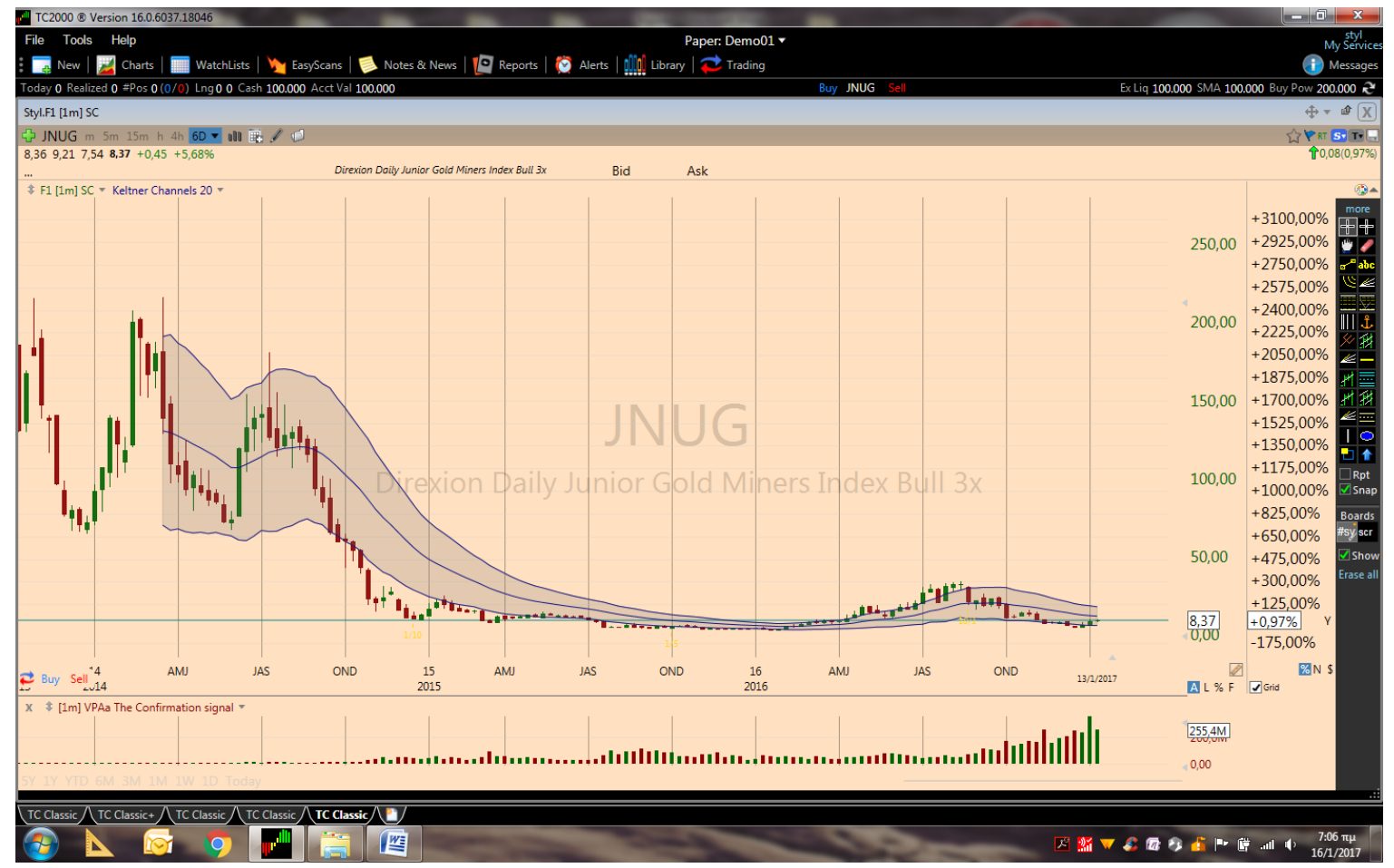

Figure 1. The die-down price action course of the JNUG leveraged ETF - weekly price-bars from 2012 to 2016 


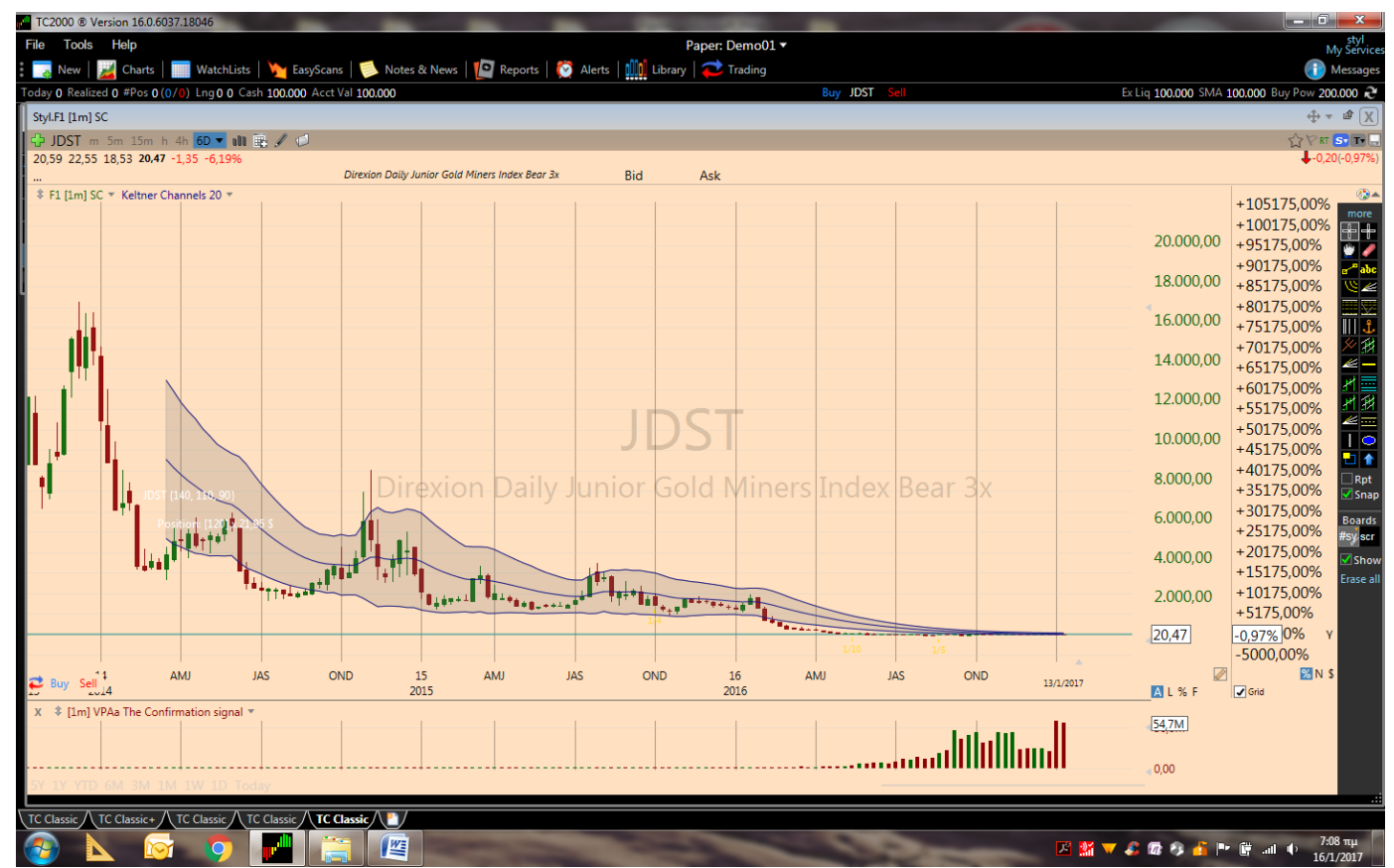

Figure 2. The die-down price action course of the JDST inverse ETF - weekly price-bars from 2012 to 2016

\section{The Temporal Leveraged ETF Anomaly}

In this Section, the innovative term temporal leveraged ETF anomaly is defined, analyzed by using the Livermore's "psychological time" and "emotional control" as parameters, and its functionality is documented in "Money Risk Management - Exit Policy" trading tactic's functions.

So, the temporal leveraged ETF anomaly is defined as a two-dimension array of TTF functionalities applied in daytime and overnight trading for any leveraged/inverse asset pair. In this definition, the first dimension is the "psychological time" at the begging of a move, while the other dimension is the "emotional control" for both: (i) opening position (what am I waiting for? Reactions or Breakouts) (Figures 3a, 3b, and 3c); and (ii) buy-and-hold position (trading off! Visual Display Unit/VDU real-time off or Machine eyeballing) (Livermore 1940/2001).

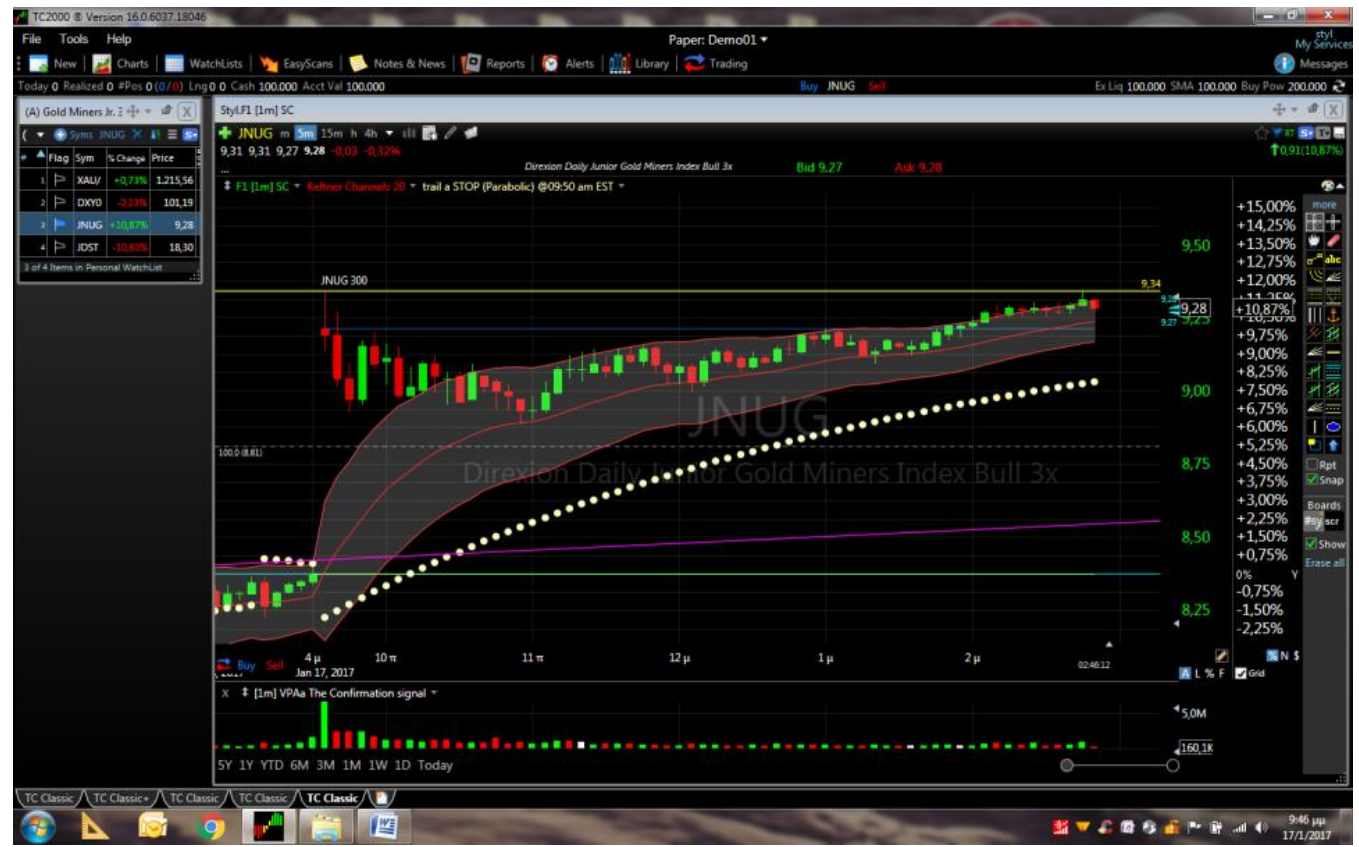

Figure 3a. What am I waiting for? 


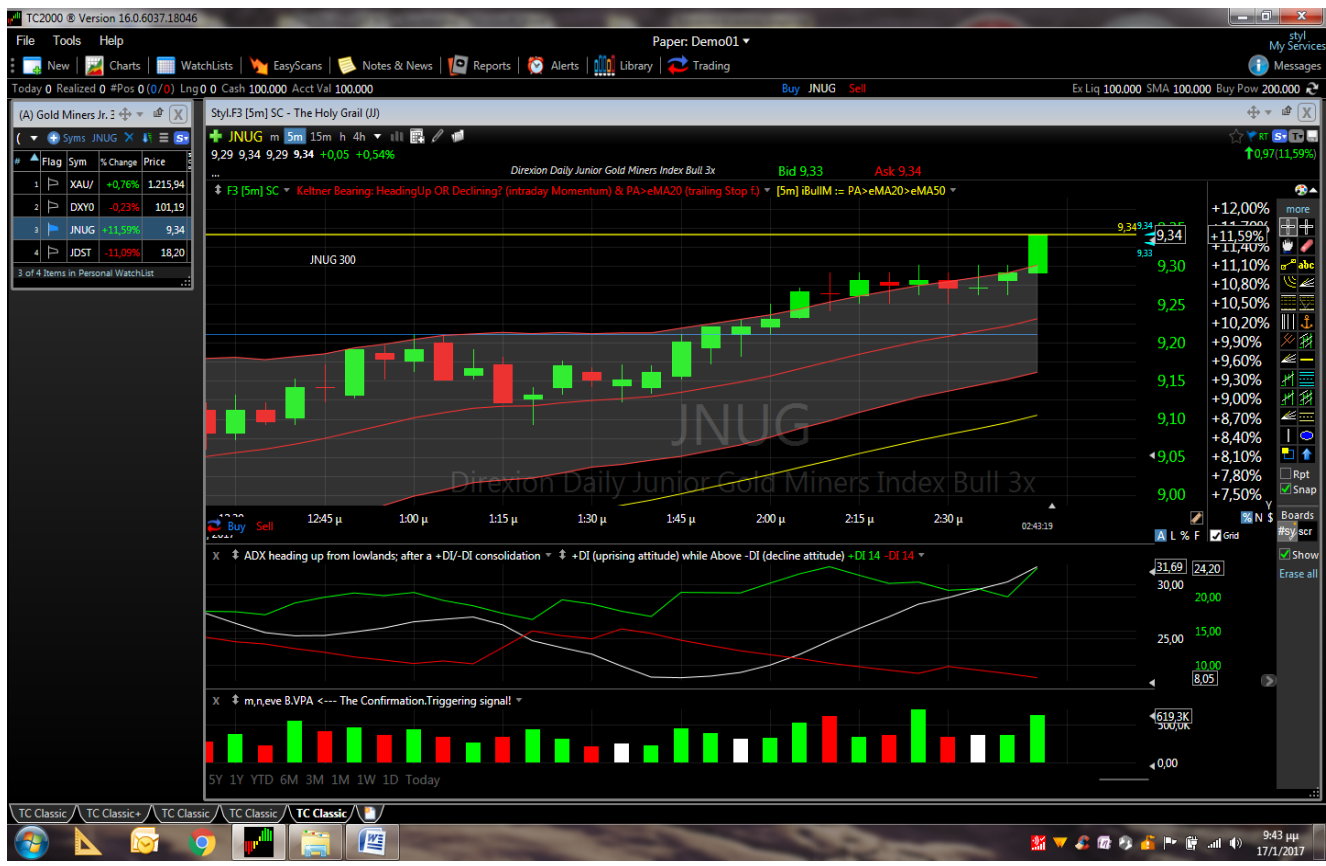

Figure 3 b. Breakout initiating but without the volume-rising confirmation

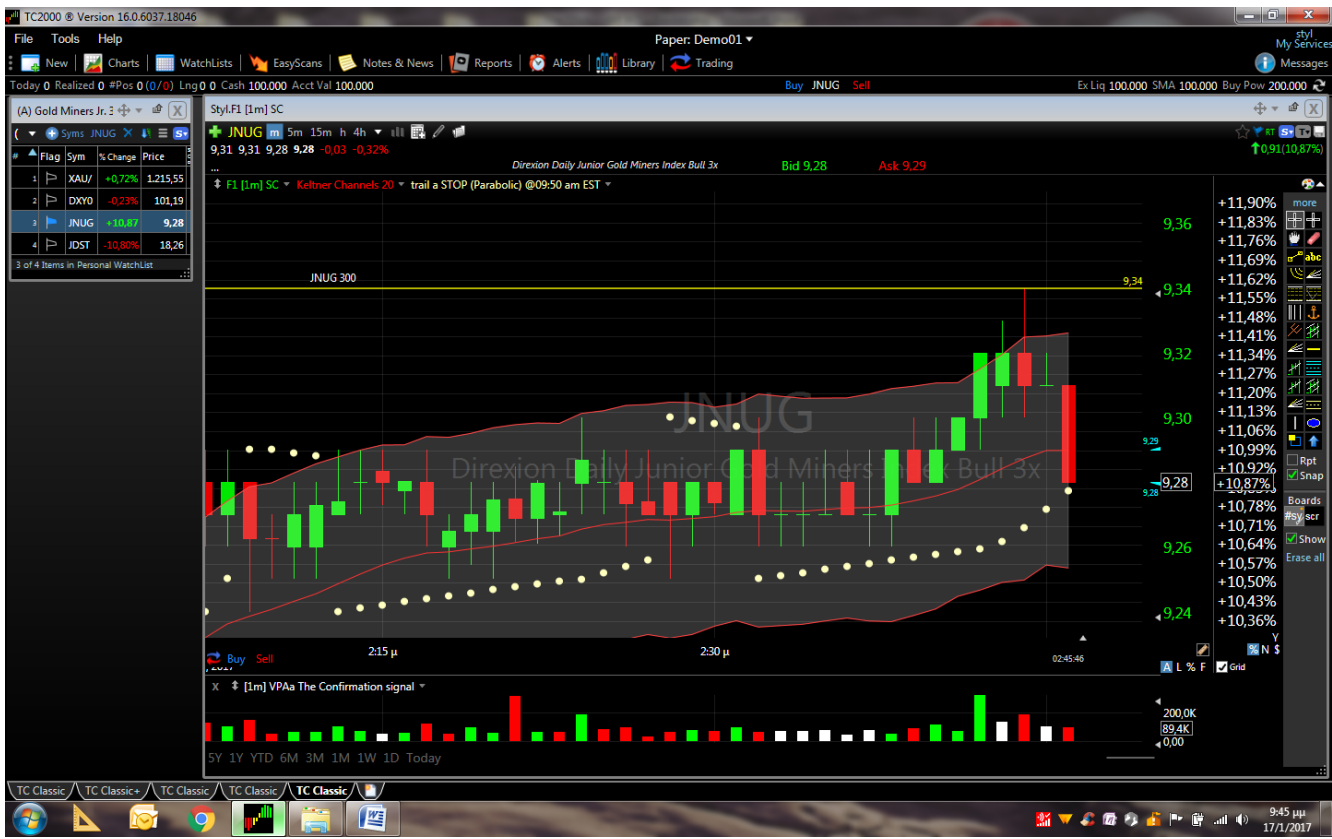

Figure 3c. A Breakout failure!

Particularly, in the proposed TTF-based two-dimensional trading-strategy approach, the following time-series are regarded as Livermore's psychological time parameters: session opening (09:30- 09:34); session morning (09:50, 10:00, 10:30 - 11:00); session noon (14:00); session evening (15:30 - 15:50); and session closing (15:57 - 16:00).

Finally, the TTF functionality is documented in a number of "Money Risk Management - Exit Policy" trading tactic's functions, like: (a) close position@psychological time 16:00; and (b) trail-a-stop for exit/close position, with exit parameters: (i) eMA(20) - exponential moving average (period: 20) cross-down; (ii) parabolic@psychological time period 09:30 - 10:30 cross-down (see Figures 3a, and 3c); (iii) uprising trend-line break-down. Following Figure 4 displays for the Money Risk Management - Exit Policy trading tactic, the "close position@psychological time 16:00" function, followed by the institutions in October 1-5, and November 8-12, 2016 (JNUG 3x ETF). 


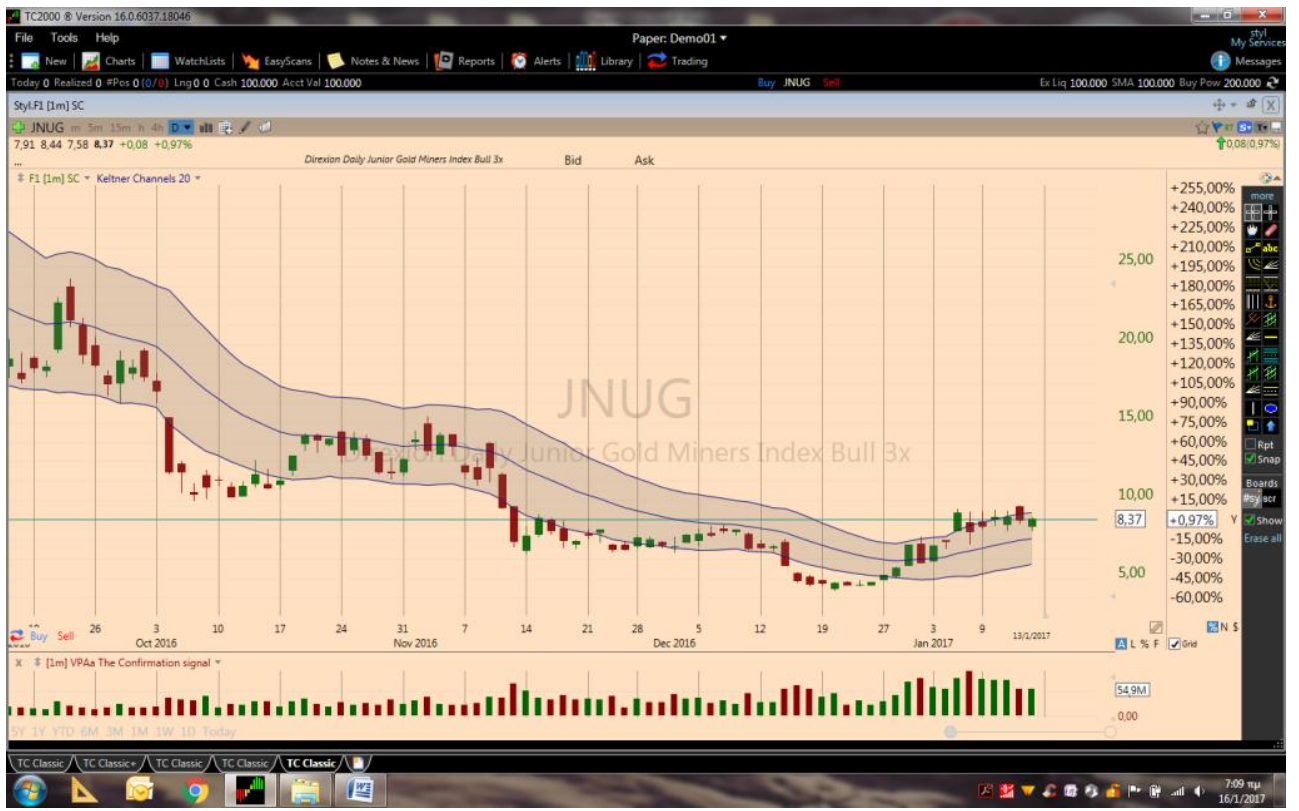

Figure 4. The "close position@psychological time 16:00” function

(Money Risk Management - Exit Policy trading tactic)

Following Figure 5 displays for the Money Risk Management - Exit Policy trading tactic, the trail-a-stop for exit/close position with exit parameter the eMA20 cross-down function, followed by the institutions in December 27-28, 2017 (JDST 3x ETF).

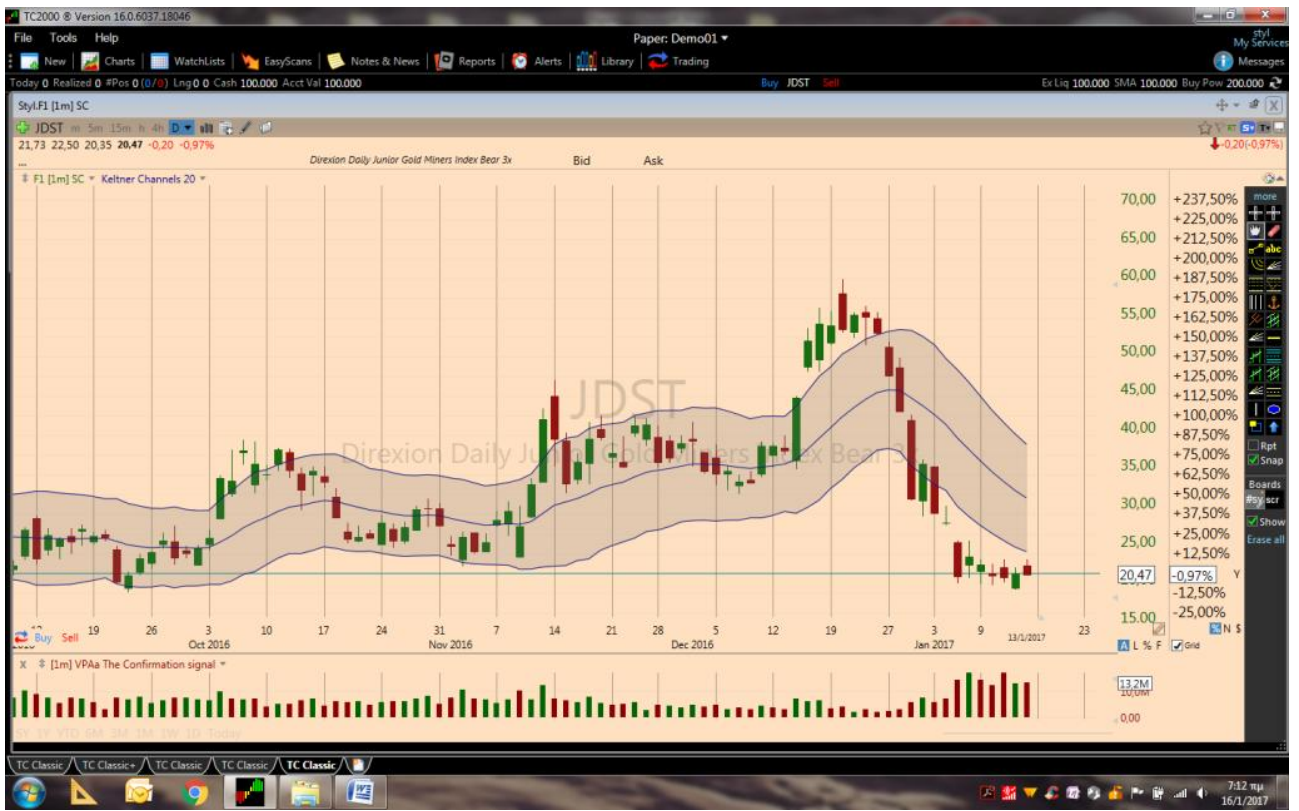

Figure 5. The trail-a-stop for exit/close position with exit parameter the eMA20 cross-down function (Money Risk Management - Exit Policy trading tactic)

In the temporal leveraged ETF anomaly trading-strategy approach, the TTF are operated only as short-term functionalities parameterized by popular price action time-frames (e.g. [1-minute], and [5-minute]); and they could be documented by time- and profit-targets in trading any asset as follows: (i) define intraday momentum trading strategies by specific time- and profit-targets; and open/close long/short positions at a specific time- and profit-target; and (ii) define swing trend-reversal strategies by consolidation price action patterns, resistance and support zones, and price action / technical indicators divergences (Little, 2010). 
The TTF temporal functionalities (e.g. psychological time TTF) operate as great warning dynamics trading signals (w!D signals) when they are related to particular candlestick patterns (e.g. Bullish Engulfing, Dark-Cloud Cover - bearish confirmation; see Figure $6 \mathrm{a}, 6 \mathrm{~b}$, and $6 \mathrm{c}$ ) or price action patterns (e.g. Head-and-Shoulders/neck-line; see Figure $6 \mathrm{~b}$, and $6 \mathrm{c}$ ). For the proposed trading strategies, these short-term patterns operate as psychological time TTF $\mathrm{w}$ !D signals awaiting the final confirmation/triggering signal (e.g. volume increase; candlestick break; Jesse Livermore's resistance pivotal-line breakout; Jesse Livermore's support pivotal-line breakdown) just before the executive order (i.e. open/close position) (Wilder, 1978; Campbell et al., 2014; Livermore, 1940/2001; Leung et al., 2015).

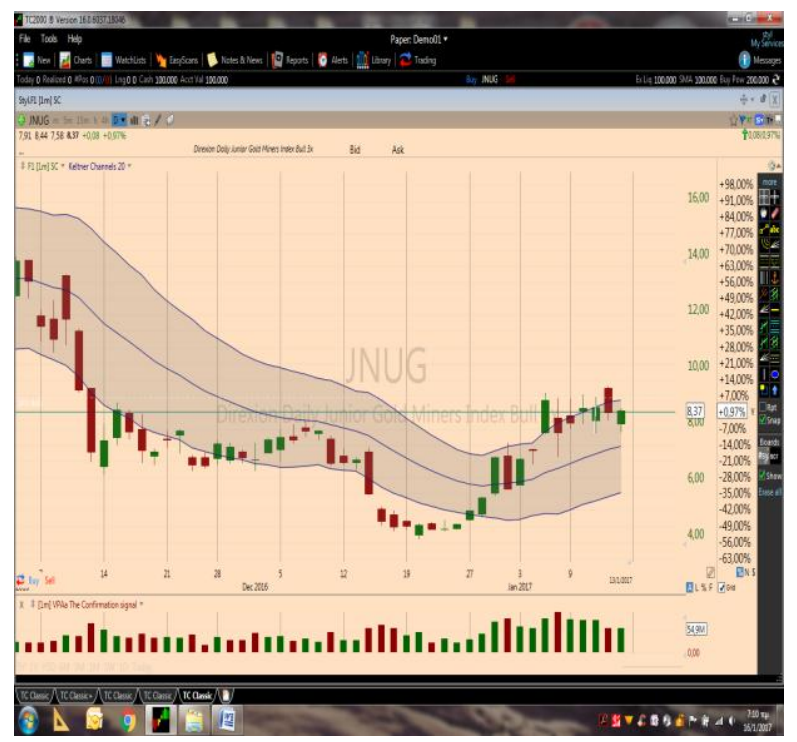

Time Warner, Inc. (TWX) NYSE 5-May-2000 4:00pm Open 56.31 High 57.88 Low 56.12 Last 56.88 volume $7.9 \mathrm{M}$ Chg +0.62 . Wime Warner 56.88 (Daily)

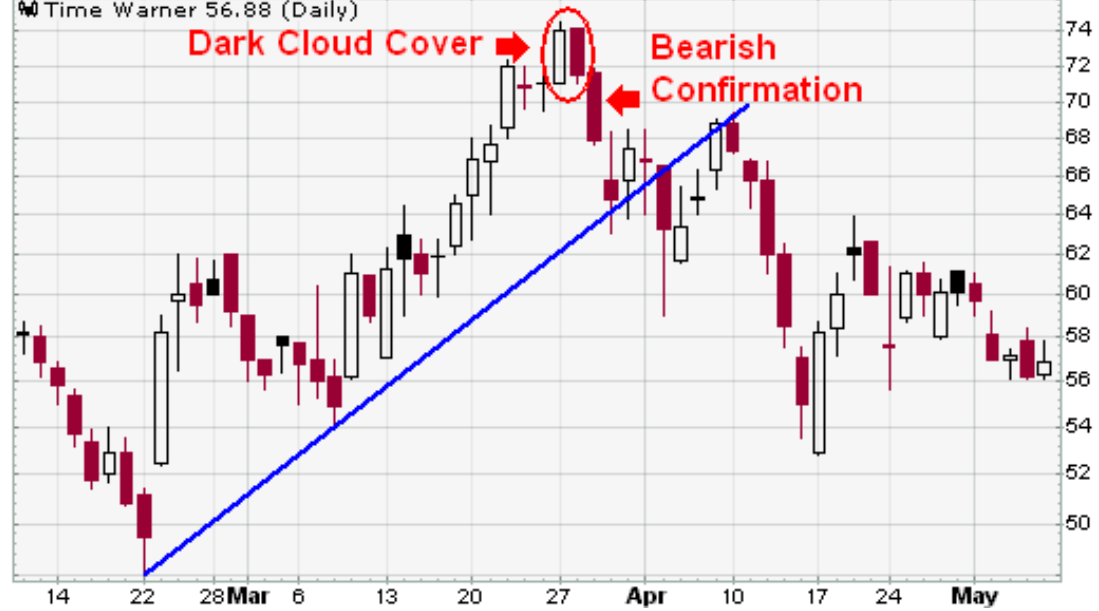

Figure 6. A Psychological time TTF as w!D signal after the appearance of: (a) the "Dark Cloud Cover with Bearish Confirmation" candlestick pattern; and (b) the "Head \& Shoulders / neck-line" PA pattern

\section{Performance Evaluation - Results}

According to financial literature (Blackrock, 2010; Avellaneda \& Zhang, 2010) for trading plans and strategies, a back-test procedure is the appropriate performance evaluation tool. So, in order to evaluate the proposed trading-strategy approach (based on the temporal leveraged ETF anomaly) we back-test it into a 5-year data-series for the 3x leveraged ETF instrument JNUG (1.1.2012 - 31.12.2016 data). This procedure has generated 1,270 trades and the results are presented in Tables 1, and 2; while a comparative return analysis for the back-testing procedure is discussed in sub-Section 4.4. 


\subsection{The Temporal Leveraged ETF in Range-Bound vs. Trending Markets}

For volatility-strategy and volatility-tactical purposes, the proposed trading-strategy approach characterized by a strong relation to overall market condition. So, trading sideways or/and choppy markets requires a different set of TTF trading functionalities rather than a trending market (Blackrock, 2010; Avellaneda \& Zhang, 2010).

Individual trades contain more information and trading TTF functionality in sideways range-bound and choppy markets than the trending ones. Hence, because the information asymmetry declines over a trending market, price changes (volatility) in trending markets are larger, reflecting in this way more private information and trading functionality. Hence, trending markets are less noisy before the opening bell-clock rather than after it (i.e. profit in trending markets occurs mainly intraday).

\subsection{The Temporal Leveraged ETF in Overnight-Position vs. Daytime-Position}

Also, for volatility-strategy and volatility-tactical purposes as well, the proposed trading-strategy approach characterized by a strong relation to trading session hours (i.e. the daytime and overnight time-series parameters). So, an intraday trading requires a different set of TTF trading functionalities rather than an overnight-position based trading (Blackrock, 2010; Avellaneda \& Zhang, 2010; Barclay \& Hendershott, 2003).

Individual trades contain more information and trading TTF functionality in after-hours (overnight) than during the daily session (intraday: 09:30 am - 04:00 pm EST). Hence, because the information asymmetry declines over the intraday trading hours, price changes overnight are larger, reflect more private information and trading functionality, and therefore they are less noisy after the closing bell-clock and before the next day's opening (i.e. profit in sideways or/and choppy markets occurs entirely overnight).

\subsection{Application Case Study - Annual Returns}

Following Table 1 is referred to the introduced temporal leveraged ETF anomaly and presents, in summary, the annual return (\%) after the application of the back-test procedure to the $3 \mathrm{x}$ instrument JNUG, for the period: $1^{\text {st }}$ January $2012-31^{\text {st }}$ December 2016 (1,920 trades generated) for trending market situations. For statistical documentation and research purposes, the returns were time-projected in two categories and they characterized as overnight-position and daytime (intraday)-position returns. In this frame, the JNUG has an annual overnight return of $-84.91 \%$ (total period return: $-430.22 \%$ ), while the annual daytime return is $58.32 \%$ (total period return: 261.19\%) (Barron's, 2017).

Additionally, a quality analysis, based on the recorded standard deviation values, says that -in trending marketsan overnight-position return trading strategy (in the case of a temporal leveraged ETF anomaly) is more risky than a daytime-position return strategy, because of the higher annual standard deviation and lower Sharpe ratio values recorded in overnight-position returns. This is why the statistical quality indicator Sharpe Ratio (which does not include in calculations the risk-free interest rate) for the overnight-position temporal leveraged ETF anomaly strategy is -0.82, compared to the 0.18 of the daytime-position temporal leveraged ETF anomaly strategy (all the above statistics apply to trending markets).

Table 1. Trending market - The temporal leveraged ETF anomaly trading-strategy approach: JNUG $3 x$ leveraged ETF: Annual Returns (\%) from a backtesting procedure (1,920 trades); $1^{\text {st } J a n u a r y ~} 2012-31^{\text {st }}$ December 2016

\begin{tabular}{ccccc}
\hline & \multicolumn{4}{c}{ Net Trading Results (\%); commission cost \$0.01 per traded share } \\
\hline & Annual Return & Annual std. dev. & Sharpe Ratio & Total Return \\
\hline Overnight-position Return Strategy & $-84.91 \%$ & $15.20 \%$ & -0.82 & $-430.22 \%$ \\
Daytime-position Return Strategy & $58.32 \%$ & $10.12 \%$ & 0.18 & $261.19 \%$ \\
\hline
\end{tabular}

Following Table 2 is referred to the introduced temporal leveraged ETF anomaly and presents, in summary, the annual return (\%) after the application of the back-test procedure to the $3 \mathrm{x}$ instrument JNUG, for the period: $1^{\text {st }}$ January $2012-31^{\text {st }}$ December 2016 (1,920 trades generated) for sideways market situations. For statistical documentation and research purposes, the returns were time-projected in two categories and they characterized as overnight-position and daytime (intraday)-position returns. In this frame, the JNUG has an annual overnight return of $91.36 \%$ (total period return: $490.82 \%$ ), while the annual daytime return is $-78.72 \%$ (total period return: $-452.29 \%$ ) (Barron's, 2017).

Additionally, a quality analysis, based on the recorded standard deviation values, says that -in sideways and choppy markets- an overnight-position return trading strategy (in the case of a temporal leveraged ETF anomaly) is less risky than a daytime-position return strategy, because of the lower annual standard deviation and higher 
Sharpe ratio values recorded in overnight-position returns. This is why the statistical quality indicator Sharpe Ratio (which does not include in calculations the risk-free interest rate) for the overnight-position temporal leveraged ETF anomaly strategy is 0.62, compared to the -0.57 of the daytime-position temporal leveraged ETF anomaly strategy (all the above statistics apply to sideways and choppy markets).

Table 2. Sideways \& choppy markets - The temporal leveraged ETF anomaly trading-strategy approach: JNUG 3x leveraged ETF: Annual Returns (\%) from a backtesting procedure (1,920 trades); $1^{\text {st }}$ January $2012-31^{\text {st }}$ December 2016

\begin{tabular}{ccccc}
\hline & \multicolumn{3}{c}{ Net Trading Results (\%); commission cost \$0.01 per traded share } \\
\hline & Annual Return & Annual std. dev. & Sharpe Ratio & Total Return \\
\hline Overnight-position Return Strategy & $91.36 \%$ & $10.71 \%$ & 0.62 & $490.82 \%$ \\
Daytime-position Return Strategy & $-78.72 \%$ & $19.29 \%$ & -0.57 & $-452.29 \%$ \\
\hline
\end{tabular}

\subsection{Comparative Return Analysis}

A comparative return analysis, according to Tables 1 and 2, indicates that the JNUG $3 \mathrm{x}$ instrument has had better annually and totally (5-year) performance under the introduced temporal leveraged ETF anomaly in intraday trading trending markets; whilst this instrument achives better results in overnight trading sideways and choppy markets. This actually confirms the notes presented in sub-Sections 4.2 and 4.3.

Tables 1 , and 2 presented the trade performance analysis results after applying the back-testing procedure on the $3 \mathrm{x}$ instrument JNUG. For statistical backtesting purposes, during this back-testing procedure, a capital of $\$ 100,000$ has been invested per trade and a commission cost of $\$ 0.01$ is regarded. This commission cost of $\$ 0.01$ per traded share results, under specific conditions, on significant (net) profit as shown in Tables 1, and 2.

Please note that in case of a commission cost of $\$ 0.02$ per share, the total net profit of both overnight-position and daytime-position return strategies would be less than zero. Even worst, if we add any slippage cost in overnight return strategy. But, thanks to internet-based low-cost brokerage nowadays available, commission cost is very low ( $\$ 0.005$ per share) and slippage cost is not applicable nowadays (Vayanos \& Woolley, 2013).

\section{Conclusions \& Discussion}

The main goal of this paper was to introduce the leveraged ETF die-down price action technical market anomaly (leveraged ETF anomaly), and then to discuss the temporal dimension and the subsequent (time-series) functionalities of this anomaly (temporal leveraged ETF anomaly) (Blackrock, 2010; Avellaneda \& Zhang, 2010; Vayanos \& Woolley, 2013).

Over the years, many studies have presented data about what academics call "market anomalies". Typically, for these anomalies, there are three common classifications: Fundamental, Technical, and Calendar-based anomalies. Also, there is another class of anomalies that simply could be referred to as "temporal" because of the time-series (timing) functionality involved. In this article we have discussed one of these "temporal" anomalies, called the temporal leveraged ETF market anomaly (Chemmanur, He, \& Hu, 2009; Wilder, 1978; Campbell et al., 2014; Livermore, 1940/2001).

The introduced anomaly could be characterized as a trading-strategy approach rather than as a documented trading strategy; but if they parameterized by the time and particular by the psychological time during the overnight and intraday time periods, then they would respected as time-series temporal trading strategies. That is to say, it has a temporal dimension because it uses the Jesse Livermore's "psychological time" as parameter in both functions: (i) "emotional control" for opening position at the beginning of an intraday or short-term move and thereafter for holding this position; and (ii) in "money risk management - exit policy" for closing position.

Price action is more efficient and therefore more information and trading functionality is revealed per time during the intraday (daytime) session than after-hours (overnight). However, the after-hours overnight low trading volume generates great volatility and therefore significant trading opportunities (albeit inefficient) appear and offer excellent chances for price action analysis and opportunities for the introduced in this paper trading-strategy approach (Avellaneda \& Zhang, 2010; Little, 2010; Wilder, 1978; Campbell et al., 2014; Livermore, 1940/2001; Leung et al., 2015).

The presented research showed that the proposed temporal leveraged ETF anomaly accumulates profit entirely overnight in a range-bound market, while in a trending market the profit occurs intraday. These findings for the leveraged ETF instruments reject classical theories of trending and sideways markets returns. 
After back-testing our research in available 5-year data for the JNUG/JDST 3x leveraged ETF pair (gold miners juniors), and by examining the trading activities of long-term position shareholders, swing traders, speculators and hedgers, we found that overnight-position speculators, in sideways markets, profit from the proposed temporal leveraged ETF trading strategy approach at the expense of hedgers, and daytime swing traders, in trending markets, profit from the proposed temporal leveraged ETF trading strategy approach at the expense of long-term investors. So, a diversified portfolio of trading strategies based on the introduced temporal leveraged ETF anomaly -for a $3 x$ instrument of a volatile Sector- could deliver substantial abnormal returns.

The main achievement of this paper was the introduction of the new anomaly, the temporal leveraged ETF market anomaly, armed with innovative TTF functionalities relating to "psychological time" at the beginning of a move (Livermore, 1940/2001) during the daytime and the overnight trading sessions.

The temporal (time-series) momentum and trend-reversal trading approaches discussed in this paper represent some of the most direct tests of the random walk hypothesis and a number of prominent behavioral and rational asset pricing theories. Our findings present new evidence and challenges for those theories and for future research.

\section{Acknowledgments}

I would like to thank the anonymous reviewers for their careful reading of the manuscript and their many insightful comments and suggestions. Also, the financial support (covering mainly the CoT/CFTC, Zacks, and the Barron's \& WSJ.com market data expenses) from the EU/LLP Programme "EPOCHE 2014" (with Project No. 2013-1-GR1-ERA10-15376) is gratefully acknowledged.

\section{Conflicts of Interest}

The author has not declared any conflict of interest with the companies and market quotes appeared on this article. Also, on writing and publishing this paper she has no position in any stocks, ETF, ETN and trading instruments mentioned.

\section{Disclaimer}

The approaches and trading strategies provided on this article are general information services for the public. The author is not an investment advisor, and she does not endorse or recommend any securities or other investments. Market quotes and certain other information on this article, as well as reference materials or links to sites, have been compiled unbiased from publicly available sources believed to be reliable and are for general informational and research purposes only. The accuracy or completeness of the information, approaches, plans and trading strategies contained herein is not guaranteed and is not intended to be relied upon for investment purposes.

\section{References}

Ahn, D. H., Conrad, J., \& Dittmar, R. F. (2003). Risk adjustment and trading strategies. The Review of Financial Studies, 16, 459-485. http://dx.doi.org/ 10.1093/rfs/hhg001

Asness, C., Moskowitz, T. J., \& Pedersen, L. H. (2013). Value and Momentum Everywhere. The Journal of Finance, LXVIII(3), 929-985. http://dx.doi.org/10.1111/jofi.12021

Avellaneda, M., \& Zhang, S. (2010). Path-Dependence of Leveraged ETF Returns. SIAM Journal of Financial Mathematics, 1, 586-603. http://dx.doi.org/10.1137/090760805

Barclay, M. J., \& Hendershott, T. (2003). Price Discovery and Trading After Hours. The Review of Financial Studies, 16(4), 1041-1073. http://dx.doi.org/10.1093/rfs/hhg030

Barron's Financial Investment News and Market Data. (2017). Retrieved from http://www.barrons.com/data; and http://www.wsj.com; and http://www.wsj.com/europe

Basdekidou, V. A. (2015). Functionality, Returns and Efficiency before and after the Debt Crisis: An Empirical Analysis of the Greek Stock Market (Unpublished doctoral dissertation). Bulgarian Academy of Sciences Economic Research Institute, Bulgaria.

Basdekidou, V. A. (2016a). IPO Trading with Short-term and Intraday Temporal Functionalities. Business and Economics Journal, 7(4). http://dx.doi.org/10.4172/2151-6219.1000257

Basdekidou, V. A. (2016b). Personalized Temporal Trading Functionalities Engaged in Calendar Market Anomalies: Empirical Evidences from the 2007 and 2009 Financial Crises. Journal of Business \& Financial Affairs, 5(4). http://dx.doi.org/10.4172/2167-0234.1000225

Basdekidou, V. A. (2017a). Seasoned Equity Offerings as Technical Market Anomalies: Long-Term Temporal Trading Functionalities. International Journal of Economics and Finance, 9(1), 96-105. 
http://dx.doi.org/10.5539/ijef.v9n1p96

Basdekidou, V. A. (2017b). The Overnight Return Temporal Market Anomaly. International Journal of Economics and Finance, 9(3), 1-10. http://dx.doi.org/10.5539/ijef.v9n3p1

Basdekidou, V. A. (2017c). The Momentum \& Trend-Reversal as Temporal Market Anomalies. International Journal of Economics and Finance, 9(5), 1-20. http://dx.doi.org/10.5539/ijef.v9n5p1

Basdekidou, V. A., \& Styliadou, A. A. (2017). Technical Market Anomalies: Leveraged ETF Trading with Daily and Intraday Temporal Functionalities. Business and Economics Journal, 8(1). http://dx.doi.org/10.4172/2151-6219.1000275

Blackrock, Inc (2010). ETF Landscape Year End 2009 Preview Report. Retrieved from http://www.BlackRock.com

Campbell, J. Y., Giglio, S., Polk, C., \& Turley, R. (2014). An Intertemporal CAPM with Stochastic Volatility. London School of Economics and Political Siences working paper, LSE London, UK. Retrieved from https://pdfs.semanticscholar.org/0044/748cabfc0ee3f7fdeea1992ce8efd7aaaa5f.pdf

Chemmanur, T. J., He, S., \& Hu, G. (2009). The role of Iinstitutional Investors in Seasoned Equity Offerings. Journal of Financial Economics, 94, 384-411. http://dx.doi.org/10.1016/j.jfineco.2008.12.011

Cheng, M., \& Madhavan, A. (2009). The Dynamics of Leveraged and Inverse-Exchange Traded Funds. Journal of Investment Management, 7(4), 43-62. Available at SSRN: https://ssrn.com/abstract=1393995; http://www.q-group.org/wp-content/uploads/2014/01/Madhavan-LeverageETF.pdf

Direxion Investments. (2017). ETFs and Funds: Bold trades on Gold Miners - in either direction. http://www.direxioninvestments.com/; http://www.direxioninvestments.com/gold-miners

Edelen, R. M., Ince, O., \& Kadlec, G. B. (2015). Institutional Investors and Stock Return Anomalies. E- Journal SSRN. http://dx.doi.org/10.2139/ssrn.2359744

Lefevre, E. (2010). Reminiscences of a Stock Operator. (J. D. Markman, Annotated edition, p. 423). Hoboken, NJ: John Wiley \& Sons, Inc. (Original work published 1923).

Leung, T., Lorig, M., \& Pascucci, A. (2015). Leveraged ETF implied volatilities from ETF dynamics. Retrieved from http://www.spdr-etfs.com

Little, P. K. (2010). Inverse \& Leveraged ETFs: Not Your Father's ETF. The Journal of Index Investing, 1(1), 83-89. http://dx.doi.org/10.3905/jii.2010.1.1.083

Livermore, J. (2001). How to Trade in Stocks. (R. Smitten, Translation, p. 179). New York, NY: McGraw-Hill. (Original work published 1940).

Lou, D., Polk, C., \& Skouras, S. (2016). A Tug of War: Overnight versus Intraday Expected Returns. London School of Economics and Political Sciences working paper, LSE London, UK. Retrieved from http://personal.lse.ac.uk/loud/overnightmom.pdf

Malkiel, B. G. (2003). A Random Walk Down Wall Street (p. 463). New York, NY: W. W. Norton \& Company. Retrieved from http://http://site.iugaza.edu.ps/wdaya/files/2013/

Moskowitz, T. J., Ooi, Y. H., \& Pedersen, L. H. (2012). Time series momentum. Journal of Financial Economics, 104, 228-250. http://dx.doi.org/ 10.1016/j.jfineco.2011.11.003

Nguyen, X. M., \& Tran, Q. T. (2016). Dividend Smoothing and Signaling Under the Impact of the Global Financial Crisis: A Comparison of US and Southeast Asian Markets. International Journal of Economics and Finance, 8(11), 118-123. http://dx.doi.org/10.5539/ijef.v8n11p118

Ogden, J. P., \& Wu, S. (2013). Reassessing the Effect of Growth Options on Leverage. Journal of Corporate Finance, 23, 182-195. http://dx.doi.org/10.1016/j.jcorpfin.2013.08.008

Styliadis, A. D. (2007). E-learning Documentation of Historical Living Systems with 3-d Modeling Functionality. Informatica, 18(3), 419-446. Retrieved from http://www.mii.vu.lt/informatica/pdf/INFO686.pdf

Styliadis, A. D., \& Vassilakopoulos, M. G. (2005). A Spatio-Temporal Geometry-based Model for Digital Documentation of Historical Living Systems. Information \& Management, 42(2), 349-359. http://dx.doi.org/10.1016/j.im.2004.01.006

Van Eck. (2017). https://www.VanEck.com (formely Market Vectors ETFs)/

Vayanos, D., \& Woolley, P. (2013). An Institutional Theory of Momentum and Reversal. Review of Financial 
Studies, 26(5), 1087-1145. https://doi.org/10.1093/rfs/hht014

Wilder, W. J. Jr. (1978). New Concepts in Technical Trading Systems (p. 130). Hunter Publishing Company. Winston-Salem \& Greensboro, NC: Trend Research. Library of Congress Card Catalog No. 78-60759. Retrieved from http://rls.bsd.com.br/ rls/Classicos/Welles\%20Wilder\%20-\%20New\%20Concepts\%20in\%20Technical\%20 Trading\%20Systems.pdf

Worden. (2017). Retrieved from http://www.tc2000.com/

\section{Copyrights}

Copyright for this article is retained by the author(s), with first publication rights granted to the journal.

This is an open-access article distributed under the terms and conditions of the Creative Commons Attribution license (http://creativecommons.org/licenses/by/4.0/). 